\title{
ResearchArticle
}

\section{Combining ability analysis for yield and yield components in rice (Oryza sativa L.)}

Ashish Goswami

\section{SUMMARY}

With the aim of increasing interest in exploitation of heterosis in rice, there is an urgent need to make available various CMS lines and good restoration capability lines for combining ability tests. The knowledge of combining ability is useful to assess nicking ability in self-pollinated crops and at the same time elucidate the nature and magnitude of gene actions involved, provides to the breeder about insight of nature and relative magnitude of fixable and non-fixable genetic variances i.e. due to dominance or epistatic components. This study provides useful information for the selection of donor parents for effective breeding programme. Such informations are required to design efficient breeding programmes for rapid dynamic and strategic crop improvement for quantitative along with qualitative nature of traits. Variation with in crosses and parents were significant for all the characters and also magnitude of variance among parents vs crosses were also significantly for all characters except day to 50\% flowering. The SCA variances were higher than the corresponding GCA variances for all the traits. The significant and positive gca effects for grain yield per plant were exhibited only by 3 males namely, Swarna, NDRK 5026 and NDRK 5032 which were found to be good general combiners. Among 24 hybrids studied, none of the hybrids exhibited high sca effects for all 10 characters.

Key Words : Rice, GCA, SCA, Hybrid, Line x tester

How to cite this article : Goswami, Ashish (2018). Combining ability analysis for yield and yield components in rice (Oryza sativa L.). Internat. J. Plant Sci., 13 (1): 55-59, DOI: 10.15740/HAS/IJPS/13.1/55-59.

Article chronicle : Received : 06.10.2017; Revised : 15.11.2017; Accepted : 29.11.2017 